\title{
NGO engagement in the sanitation sector: opportunities to maximise benefits
}

\author{
N. Carrard*, D. Pedi**, J. Willetts* and B. Powell** \\ * Institute for Sustainable Futures, University of Technology, Sydney (Email: Naomi.Carrard@uts.edu.au; \\ Juliet.Willetts@uts.edu.au) \\ ** International WaterCentre (Email: danielle@worldtoilet.org; B.Powell@watercentre.org)
}

\begin{abstract}
Non-government organisations (NGOs) have long played a role in delivering sanitation services to communities in Southeast Asia and Pacific countries, particularly in rural areas. In contrast with large scale infrastructure focused initiatives, NGO programs commonly focus on building linkages between technical and social realms. Drawing on the breadth and depth of NGO experiences, there are opportunities for NGOs to play a greater role in the sanitation sector and to work in partnership with other actors including utilities and government agencies to ensure both 'hardware' and 'software' components of sanitation are built in to project design and delivery to maximise community benefits and ensure longer term system sustainability. This paper discusses these issues and considers how the contribution of NGOs to the sanitation sector in developing countries might be enhanced. The paper is based on recent research for the Australian Agency for International Development (AusAID) intended to guide investment in the water and sanitation sectors of Asia and Pacific partner countries, exploring the potential for increased NGO engagement. The paper presents findings of the research concerning NGO roles and approaches, discusses existing NGO activities in the sanitation sector in Vietnam and Timor Leste and identifies strategies for NGOs and for other sector actors including utilities and government agencies to maximise the benefits of NGO engagement in the sanitation sector.
\end{abstract}

\section{Keywords}

Non-government organisations (NGOs), sanitation, development effectiveness, Vietnam, Timor Leste

\section{INTRODUCTION}

Achieving the Millennium Development Goal (MDG) to halve the number of people without access to improved sanitation presents a substantial challenge for countries in Southeast Asia and the Pacific. In recognition of the failures of latrine construction projects to adequately bring about the use of these facilities or the adoption of hygiene practices, there is a growing emphasis on the need to focus on 'software' elements of sanitation initiatives rather than on 'hardware' or technical components. Indeed, epidemiological research suggests that, the single hygiene behaviour of hand washing with soap can reduce incidence of diarrhoea by up to 43\% (Curtis and Cairncross 2003). What has been learnt in the sector over many years is the need for strong community engagement and social and behavioural change processes to accompany more traditional 'hardware' solutions (Bartram et al. 2005; Hardi 2000). In the context of wider 'hygiene improvement' programs, sanitation initiatives must consider how to support household investment and behaviour change, rather than simply building and financing more toilets (WSSCC/WHO 2005).

Compared to water, sanitation suffers from lack of expressed 'demand' (Cairncross 2003). Few unserved households are fully aware of the invisible costs of inadequate sanitation, including poor health, lower productivity, inconvenience and environmental degradation. Since these households are usually the poor and marginalised, existing demand for sanitation is often ignored (Robinson 2007). There is therefore a need for well-facilitated engagement processes to encourage articulation of demand at the household and community level, including marketing, promotion and educational 
strategies (de Bruijne et al. 2007). Such processes are only possible through an in-depth understanding of what people do and, more importantly, what they want. There is also a need for sustainable business models to ensure that increased demand is met by adequate and reliable supply, with a shift from top down supply-driven projects to an emphasis on bottom up, demand-led approaches.

Successful sanitation initiatives make the essential links between technical and social realms, ensuring projects are locally owned, demand driven, linked to hygiene messages and that the capacity to undertake on-going maintenance is locally developed. Successful approaches ensure that sanitation and hygiene interventions are selected based on their appropriateness to particular contexts and in response to the needs and desires of different user groups (de Bruijne et al. 2007). Finally, successful approaches require thinking holistically about the various dimensions of sanitation systems including the health, environmental, technological, economic, socio-cultural and institutional aspects of sanitation systems (SuSanA 2007).

With a tradition of local level community engagement, NGOs have a comparative advantage in addressing some of these critical components of successful sanitation initiatives. Working with households and communities, they are well placed to add value to sanitation initiatives at the project, program and policy levels. NGOs play (and are good at playing) a variety of roles in the sanitation sector and have been credited with developing, trialling and promoting a number of innovative and locally-appropriate approaches. They are known for being advocates of equitable, sustainable and cost-effective development and for playing a critical role as intermediaries, for example between communities and utilities or other service providers. Building on foundations of successful approaches, there is potential for the range of actors in the sanitation sector to engage more closely with NGOs drawing on their strengths and collaborating to achieve more successful and sustainable sanitation outcomes.

This paper is based on a study undertaken by researchers from the International WaterCentre and the Institute for Sustainable Futures at the University of Technology, Sydney. The research was commissioned by the Australian Agency for International Development (AusAID) to assist with planning a rapid increase in its water and sanitation investments in the Asia-Pacific in the coming two years (2009-2011), with the primary objective to develop a strategic approach for how AusAID can engage with NGOs in the water and sanitation sector. This paper draws on the study, characterising NGO functions and activities in facilitating access to improved sanitation and exploring potential links and opportunities for collaboration between NGOs and other sector actors including governments, service providers, donors and education/training institutions. Following an overview of research methods, the paper describes roles played by NGOs in the sanitation sector and presents case studies of NGO activities and potential future roles in two case study countries, Vietnam and Timor Leste. The paper concludes with a discussion of potential opportunities for NGOs and others to maximise the benefits of collaboration, drawing on the relative strengths of different actors to facilitate successful provision of improved sanitation.

\section{METHODS}

The study focused on 10 countries across Southeast Asia and the Pacific including Timor Leste and Vietnam. The research was primarily qualitative in nature, with data collected from semi-structured interviews, an online questionnaire, a workshop focused on capacity building and a desktop review. ${ }^{1}$ Thirteen Australian-based NGOs and 73 in-country NGOs were consulted with an

\footnotetext{
${ }^{1}$ See Willetts et al. (2008) for a more detailed description of the research methodology.
} 
additional 50 NGOs responding to the online questionnaire. NGO interviews were conducted using a consistent semi-structured interview guide and question sheet. Questions focused on NGO roles (including strengths and weaknesses), existing water and sanitation activities and approaches used, monitoring and evaluation techniques, the nature and strength of links to other sector actors (e.g. governments and other partners) and staff capacity and skills. In addition to NGOs, interviews were conducted with 10 sector experts and 14 AusAID staff.

\section{RESULTS AND DISCUSSION \\ NGOs and other sanitation sector actors}

The sanitation sector is characterised by complex institutional settings in which multiple actors have a stake in providing and maintaining sanitation services. Government are responsible for the creation and implementation of policies and regulatory systems and also commonly for service provision. Private sector actors play an important role as direct service providers and/or supply chain organisations, indeed most sanitation systems for the poor have been built through the informal private sector (usually small independent providers) and the natural market (Obika 2004). In countries across Southeast Asia and the Pacific donors play a role in financing, designing and delivering sanitation services. A range of education and training institutions are also important to the sector in building a skills base and driving research and innovation across technical and soft system components of sanitation. At the local level, communities are critical stakeholders as end users and consumers and are often also active in the design, construction and maintenance of sanitation systems.

There is a great deal of overlap and opportunity for different sanitation sector actors to work together including with NGOs. NGOs can be classified as 'intermediate level organisations' within the water and sanitation sector framework proposed by Visscher et al. (2006) and as such take on functions as 'interface' agents between national level agencies and local level service providers. These functions include mediating between actors at different scales and providing capacity building and support for service providers. In addition to playing intermediate level roles, NGOs in the sanitation sector also commonly play a more direct role in service provision and/or engaging directly with end users at the community level providing sanitation and hygiene education and stimulating user demand (Figure 1). 


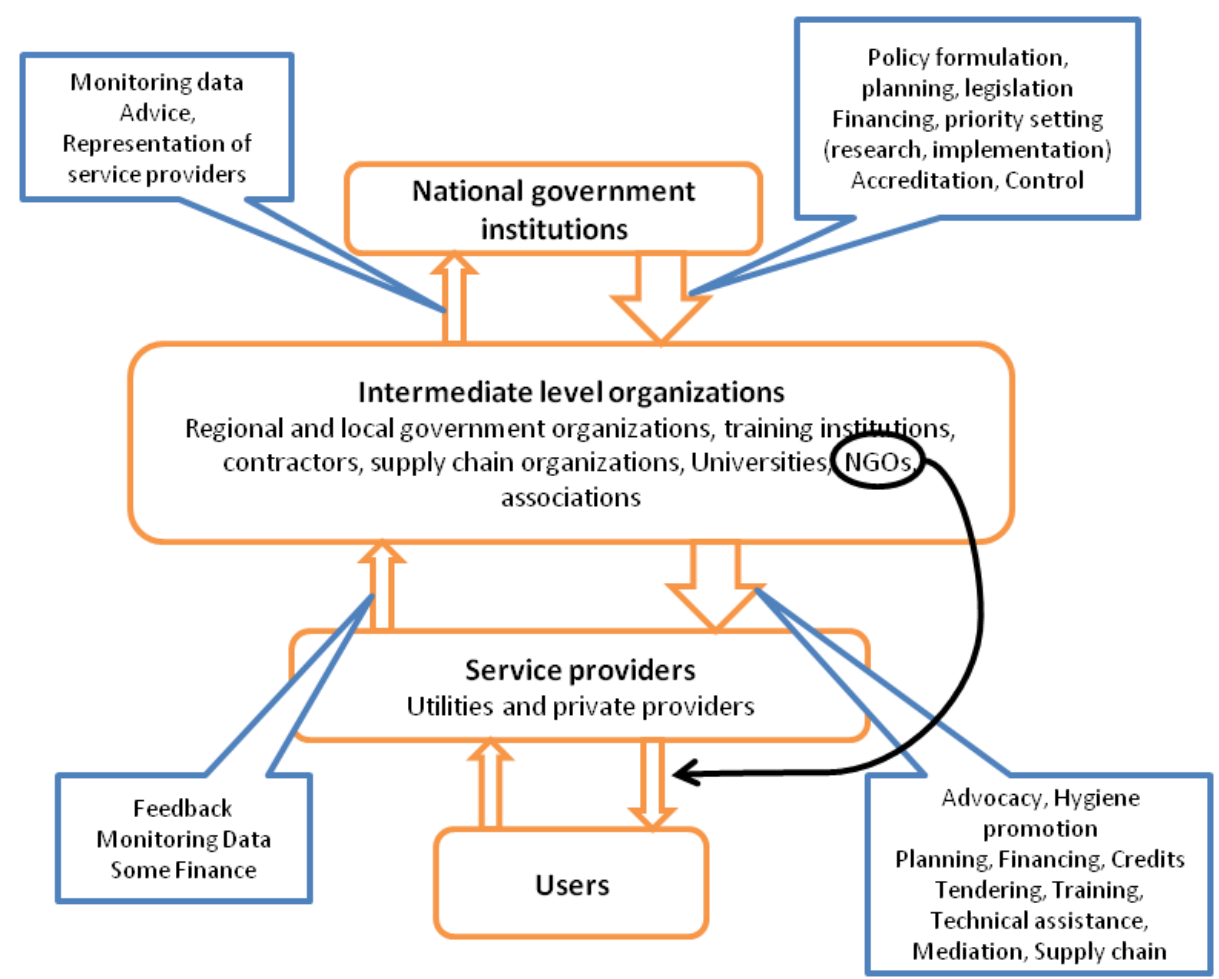

Figure 1 Intermediate level, the interface between national governments and service providers (adapted from Visscher et al. 2006)

\section{NGO Roles in the Sanitation Sector}

The research found the majority of NGOs consulted have considerable strengths and play important and varied roles in the sanitation sector. NGOs have assisted in facilitating better access for the poor to sanitation services and typically offer on-the-ground impact in increasing access to services within relatively short timeframes through established community relationships. They often have the ability to reach remote places or illegal settlements where service provision is challenging and have been shown to be adept at setting sanitation within a holistic development frame, commonly taking an integrated and longer-term programmatic approach to meeting community needs. They are adaptable to circumstance and in each country studied as part of the research can be seen taking on different roles in response to the local community and policy contexts. At the same time, NGOs are able to draw on international experience through their networks of practitioners, facilitating the exchange of new ideas to from one area to the next. These different NGO roles are each of considerable importance to the sector.

Based on NGOs interviewed and surveyed and the review of literature, the roles of NGOs in the sanitation sector in focus countries were found to range from community education through to research and policy advocacy. The various roles played by NGOs in the sanitation sector can be broadly grouped into six categories:

1. Facilitation of service delivery including direct service provision (particularly in emergency and humanitarian relief contexts or in areas characterised by extreme poverty or geographical remoteness) or playing an intermediary or broker role between communities and service providers.

2. Community education, awareness-raising, sanitation and hygiene promotion and marketing including stimulating demand, gender sensitive approaches, supply chain strengthening and implementing behaviour change programs. 
3. Building partnerships and promoting networking between different sector actors including representing community views to governments and service providers and translating and communicating national policies and regulations to the local level.

4. Capacity building for local governments, service providers, in-country civil society groups and end users (households and communities).

5. Research and innovation including demonstration and piloting of innovative and locally adapted approaches and technologies.

6. Engaging in policy dialogue including promoting proven approaches and technologies, communicating lessons learnt, communicating community needs, advocating gender equity and monitoring the effectiveness of programs and government initiatives.

The broad strengths NGOs bring to these roles need to be considered with reference to limitations of NGO roles and activities. Whilst there are many examples of success, it is also true that NGOs have at times played potentially detrimental roles (though through good intentions). Examples include when NGOs are not sufficiently engaged with the sector in a given country and therefore fail to coordinate with other actors effectively, or where they lack sufficient technical expertise for the work required or where they, like others, have provided hardware without sufficient software in their approach. One weakness apparent in some countries studied was in capturing of evidence of impact and sharing lessons to enable wider replication. The extent to which NGOs addressed critical gender aspects of sanitation in their initiatives was also variable, though NGOs tend to address gender to a greater extent than most other actors in the sanitation sector. Although not unique to the NGO sector, issues related to long term sustainability, in particular ensuring on-going use, maintenance and operation after the life of a project, presented significant challenges for NGOs in most countries examined. Finally, some NGOs struggled with a tendency to develop parallel service delivery structures which could potentially circumvent rather than build upon and strengthen existing initiatives and in-country institutions. This was exacerbated when NGOs were not sufficiently engaged with the sector in a given country where they were conducting activities.

The following sections discuss NGO roles in the context of Vietnam and Timor Leste, noting the areas where NGO capabilities could be further developed to increase their potential and relevance to the sanitation sub-sector.

\section{Lessons from Vietnam}

Access to sanitation and water in Vietnam has progressed at a faster rate than in neighbouring countries. Based on 2006 data, 65\% have access to sanitation with higher levels of access in urban than rural areas (WHO/UNICEF, 2008). National level data produced by UNICEF presents a more detailed picture comparing access figures with government standards and targets. For example, according to the 2006 National Baseline Survey although 75\% of rural households have latrines, only $18 \%$ of households have latrines that meet Ministry of Health (MOH) 2005 hygiene standards (UNICEF, 2007). Similarly, although $73 \%$ of schools have latrines, only $11.7 \%$ have latrines that meet $\mathrm{MOH}$ hygiene and operation and maintenance standards and $21.3 \%$ of schools reported that students defecate in forests, gardens, fields, beaches and streams or river banks. The survey also revealed poor knowledge about handwashing and lower than expected safe drinking water practices.

NGOs active in the Vietnam sanitation sector play roles in facilitation of service delivery, community education and awareness raising, capacity development, research and innovation and to 
a lesser extent engaging in policy dialogue and advocacy. International NGOs (INGOs) along with private sector organisations are the key non-government actors in the sanitation sector in Vietnam. INGOs currently active in the promotion of sanitation and hygiene include, for example, Plan, the Netherlands Development Organisation SNV, Oxfam, World Vision, East Meets West and International Development Enterprises (IDE). Interviews indicated that local civil society is still in early stages of development and national NGOs are typically poorly resourced in terms of financial and human capacity.

Based on a preliminary analysis of interview data, the following presents an overview of NGO roles and opportunities to further develop linkages with other sector players.

Facilitation of service delivery. Most INGOs active in the sanitation sector in Vietnam play a role in facilitating sanitation service delivery as part of water and/or sanitation focused projects or within integrated community development programs. Sanitation projects typically include both hardware (technologies) and software (capacity building, education) components. INGO sanitation projects in Vietnam are almost wholly rural in focus with the exception of a couple of small urban demonstration projects. The rural focus of INGOs was justified by interviewees with reference to poorer access figures for rural areas and the need to support provincial and district agencies with patchy technical and management capacity in the context of decentralization. INGOs approach sanitation service delivery in a variety of ways, including developing the capacity of local service providers, stimulating local demand and market development and/or providing subsidies to support households to install latrines.

In terms of future service delivery activities, a few interviewees indicated their view that NGOs should scale back service provision projects in light of Vietnam's progression towards Middle Income Country status and focus instead on the development and demonstration of innovative approaches and technologies and support for the poorest regions and communities including mountainous, ethnic minority regions. Collaboration between government agencies, service providers and NGOs would ensure future NGO efforts in service delivery are best targeted to meet the greatest sanitation needs and complement government initiatives,

Community education, awareness-raising, sanitation promotion and marketing. Most INGOs recognise the critical importance of education and behaviour change to sustainable sanitation outcomes and include marketing and/or education in all activities, even when the focus is primarily on provision of infrastructure. IDE, for example, has been successfully trialling a market based approach using social marketing to stimulate demand and providing technical and business support to nurture local suppliers. There is general support for this approach from government agencies and NGOs consulted, however it is important to note that many INGOs stress the importance of subsidies in helping poor communities to access water and sanitation.

Within this context, there was broad support from Vietnamese Government agencies consulted for increased NGO engagement in both the water and sanitation sectors - with a particular interest in NGO support for sanitation - where NGO activities align with national programs and priorities. Interviewees suggested that NGOs could be engaged to pilot education and demand driven approaches to sanitation and hygiene promotion in line with Ministry of Health contributions to the National Target Program II for Rural Water Supply and Sanitation (NTPII). They could also play a role supporting capacity development for Village Health Workers to engage in hygiene promotion and education about sanitation.

Building partnerships and promoting networking. Within the NGO community, the NGO Resource 
Centre Water and Sanitation Working Group provides a forum for NGOs to exchange ideas, introduce innovative approaches and share lessons learnt. Most NGOs interviewed worked closely with local government partners and with mass organisations, particularly the Women's Union. Some organisations (e.g. Plan) have provincial offices in a number of locations, strengthening their capacity to form partnerships with provincial and district government agencies.

Capacity building. All consulted INGOs undertake capacity building either directly or as part of service delivery initiatives. All coordinate with Vietnamese Government agencies to plan and implement sanitation projects and all include some kind of capacity building within projects to support partner agencies. Most INGOs employ Vietnamese staff to oversee and implement initiatives and work in partnership with local and/or provincial governments as well as mass organisations. SNV is an example of an NGO that places capacity building at the centre of sanitation activities, providing technical assistance to government agencies and others involved in service provision but not directly facilitating service delivery on a project basis. There is significant scope across the NGO sector to scale-up capacity building activities - particularly in the context of decentralisation - for provincial and district level agencies tasked with service provision and maintenance of sanitation systems.

Research and innovation. NGOs play a role in Vietnam in piloting and demonstrating innovative technologies and approaches. Market based approaches have been demonstrated by IDE as noted above and informed by success from other countries, Plan is considering piloting Community Led Total Sanitation (CLTS). Borda has been trialling Decentralized Wastewater Systems (DEWATS) and the French NGO EAST (Eau, Agriculture, et Santé en Milieu Tropical) is currently undertaking a pilot program developing sanitation solutions for a peri-urban commune of Hanoi Municipality. Continued support from donors and/or government agencies for NGOs to develop and pilot innovative approaches and technologies that meet community needs could inform wider distribution of appropriate low cost technologies in both urban and rural settings, a need identified by stakeholders interviewed, particularly for rural areas.

Engaging in policy dialogue. The extent to which INGOs engage in policy dialogue is mixed. INGO sanitation initiatives are mostly project based and focused at the community level. Some INGOs have contributed (in a review and advisory role) to programmatic initiatives including the National Handwashing Initiative, but this is less common. Many focus primarily on community level project delivery, however a few also play a role in information sharing and advocacy (notably Plan and Oxfam). In line with NGO strengths linking local level engagement with innovation and policy development, there is capacity for NGOs to play more of a role within Vietnamese Government sanitation programs including NTPII and the National Handwashing Initiative. National level initiatives would benefit from greater NGO engagement in policy dialogues to share their experiences in designing, planning, implementing and evaluating water and sanitation initiatives (particularly those relating to innovative approaches and technologies). The Rural Water Supply and Sanitation Program Partnership Coordination Unit provides a facility for linking NGOs and other organisations with policy makers, and support (in terms of time and funding commitments) for representation of NGOs at workshops and other fora could facilitate information sharing between different actors.

\section{Lessons from Timor Leste}

Access to sanitation in Timor Leste is amongst the lowest in the region, and progress towards improving access has been slow. Recent estimates place national access to basic sanitation at $48.5 \%$, with $76.7 \%$ urban sanitation coverage and only $38.5 \%$ rural sanitation coverage (Interim Statistical Abstract of TSLS 2007 cited in Robinson, 2008). There is wider variability of access to 
sanitation across the rural areas, with sanitation coverage ranging from a high of $47 \%$ in rural Baucau and Lautem Districts to just 18\% in Oecussi District (Robinson, 2007). At present, the main urban population of Dili, up to $80 \%$ of whom are in informal settlements, are unserved or underserved by public sanitation services (Robinson 2007). Sanitation is lagging well behind water supply in both rural and urban areas. There is currently no national level policy for sanitation, no clear institutional home for sanitation and very limited guidance on appropriate sanitation initiatives (Robinson 2008).

It is clear that there is much scope to expand and strengthen the roles of NGOs in the sanitation subsector in Timor Leste. Based on a preliminary analysis of NGO consultations, the following sections present NGO roles and opportunities to further develop these.

Facilitation of service delivery. In the absence of significant government or private sector capacity, national and international NGOs have played a primary role in sanitation service delivery. Generally, NGOs have concentrated their work in the rural districts, with very little work in urban areas. Currently only a small number of INGOs have the capacity to undertake significant sanitation activities (e.g. with engineers or hygiene specialists on staff). These include the Federation of Red Cross, Oxfam, Plan, WaterAid, Triangle GH, Caritas, Concern and World Vision. A recent informal survey of national NGOs indicates there are approximately 14 national NGOs with capacity and experience in water and sanitation service provision. A growing trend within the NGO sector in Timor Leste is the shift towards integrated 'livelihood security' and 'community-based disaster risk management' programming, within which small scale sanitation activities are often one component. Thus, NGOs increasingly see their work as addressing community needs in a holistic way, and embedding water and sanitation work in more integrated programming.

Until the very recent introduction of Community Led Total Sanitation (CLTS) approaches, most NGOs adopted a full or partial subsidy approach to sanitation whereby communities contribute labour and some local materials (e.g. for latrine superstructure). As in many countries, the effectiveness of 'supply-led' approaches has been called into question in the Timorese context. Robinson (2007), for example, notes that although the construction of some 17,000 latrines has been financed by external agencies since 2001, there are strong indications that the bulk of these systems are not in use. Successful and sustained operation and maintenance of sanitation systems has indeed been a particular challenge for NGOs, who reported mixed results in terms of engaging district government staff in on-going maintenance.

Engaging in policy dialogue. Beyond service delivery, most NGOs see their role as incorporating elements of advocacy and policy influence, particularly in terms of representing community needs at the national level. NGOs were key stakeholders in the development of the national Rural WASH Sector Strategy, and continue to play an important role in dialogue around the formulation of a national sanitation policy. Several NGOs are also advocating for a national monitoring and evaluation framework by which to measure the relative impact of one approach against another.

NGOs are active participants in the recently formed Sanitation Working Group, chaired by the national government. This forum has provided an opportunity to discuss CLTS, which was first introduced to Timor Leste by WaterAid and Plan through pilot projects in 2007. WaterAid cofacilitated a national sector-wide workshop and training session on the approach in 2007. A number of NGOs have since taken the decision to pilot the approach, and the government has also recently announced it will trial CLTS in selected villages. It is very early days for CLTS in Timor Leste, and the debate about the whether or not to adopt the approach is still underway. Whatever the decision taken by individual organisations and the government, there is no doubt that the views and 
experiences of NGOs are shaping opinions, building consensus and impacting strongly on the discussions around a sanitation approaches and a national sanitation policy.

Research and innovation. In addition to CLTS, NGOs have taken a lead in piloting and promoting other new technologies and approaches such as composting toilets and the Participatory Hygiene and Sanitation Transformation (PHAST) methodology. NGOs also lead the sector in terms of providing critical research. The government has supported NGOs to undertake assessments of existing water supply systems in two districts, with plans to expand the scope of future assessments to include sanitation coverage, and a recent NGO study has examined community participation in water supply and sanitation.

An area where NGO research could be further expanded is the understanding of household and community gender roles and how these impact on sanitation and hygiene behaviour change. Most NGOs reported that water user groups (a key forum for discussing sanitation) tended to be dominated and led by men, despite efforts to support gender equity. Related to this, NGOs noted some challenges in discussing personal hygiene and defecation behaviours, and a greater need to gain trust and understanding of cultural and social norms and taboos. NGOs could be supported to explore barriers to women's participation and to assist in the collection of baseline data on knowledge, attitudes and practices (KAP) around sanitation and hygiene.

Capacity building. NGOs assist in sanitation capacity development at a range of levels through their partnerships as well as community and in-house training programs. NGOs have conducted Water, Sanitation and Hygiene (WASH) training courses for local participants, and have student internships and volunteer programs. Community members and district staff from the National Directorate of Water Supply and Sanitation Service (DNSAS) receive on-the-job training in design, construction, operation and maintenance.

Most INGOs work cooperatively with national NGO partners, with partnership models ranging from short-term contracts for specific implementation activities to long-term MoUs linked to organisation and technical capacity development. Increasingly, INGOs are moving towards these latter longer-term arrangements, although there is clearly scope for more work to be done in improving the quality of NGO partnerships. Several INGOs expressed their long term goal to work primarily through partners, undertaking very little direct implementation themselves. Thus INGOs could transition over time to a more explicit capacity development, mentoring and monitoring/quality assurance role.

Building partnerships and promoting networking. NGOs tend to play a strong coordination role, particularly at a district level. They tend to see their role as 'facilitator' and 'enabler', acting at the interface between government and community-level service delivery. At present, there is only one DNSAS staff officer posted in each district. NGOs reported mixed results in terms of working with these officers, indicating that success often depended on the skills and training of individual DNSAS officers and the level of access to resources (such as a motorbike and petrol) to enable visits to remote villages. These capacity and resource constraints are particularly problematic in terms of on-going operation and maintenance. Given the very low government capacity at the district and local level, NGOs try to 'fill the gap' by creating linkages and opportunities for district staff to engage, for example through the selection of priority villages, participation in village-level trainings, and on-going support in districts where NGOs have a presence. NGOs also seek to influence one another, and improve practice generally, through both formal and informal networking. NGOs tend to provide training across the sector, inviting one another to participate and learn about new approaches. 
Community education, awareness-raising, sanitation promotion and marketing. Despite the scale of the sanitation need and a growing understanding of the negative health impacts associated with poor sanitation, it seems that most NGOs (and, indeed, other sector actors such as DNSAS) are still tending to prioritise water supply. Most NGOs consulted noted that the demand for sanitation was much lower than for water supply. There are also some challenges in terms of community preference for particular sanitation technologies. For example, the types of latrine design on offer (pour-flush latrines, latrines with attached bathing rooms) often require water, despite the fact that many areas in Timor Leste are water stressed (Robinson 2007, Robinson 2008). NGOs did not report the use of sanitation marketing techniques to create demand, with most relying on hygiene education and awareness raising to create interest in latrine construction, with the exception of pilot CLTS projects. More support could be given to NGOs working on innovative approaches to creating demand and securing supply of affordable sanitation options.

\section{Strategies to Maximise the Benefits of NGO Engagement in the Sanitation Sector}

As can be seen from the breadth and nature of NGO activities in the two case study countries, there are a number of potential complementarities between NGO activities and the roles and responsibilities of others in the sanitation sub-sector. There are opportunities to enhance the role played by NGOs and learn from successful approaches, transferring knowledge and experiences within and between nations. Collaborative efforts need careful planning and management and a considered approach to defining roles and partnership arrangements. This section identifies potential areas where collaboration with NGOs could support or enhance current roles for different actors in the sector.

For government agencies, donors, training/research institutes, service providers and end users, the first step in creating opportunities is to draw on and engage with NGO strengths is to identify areas of common interest and approach. This requires thinking about complementarities with reference to each actor's scope of work and organisational skills base. Figure 2 maps sanitation sector actors alongside roles played by NGOs, illustrating the many potential opportunities for engagement between NGOs and other sector actors. A discussion of the ways in which greater engagement could benefit the sanitation sector is below. 


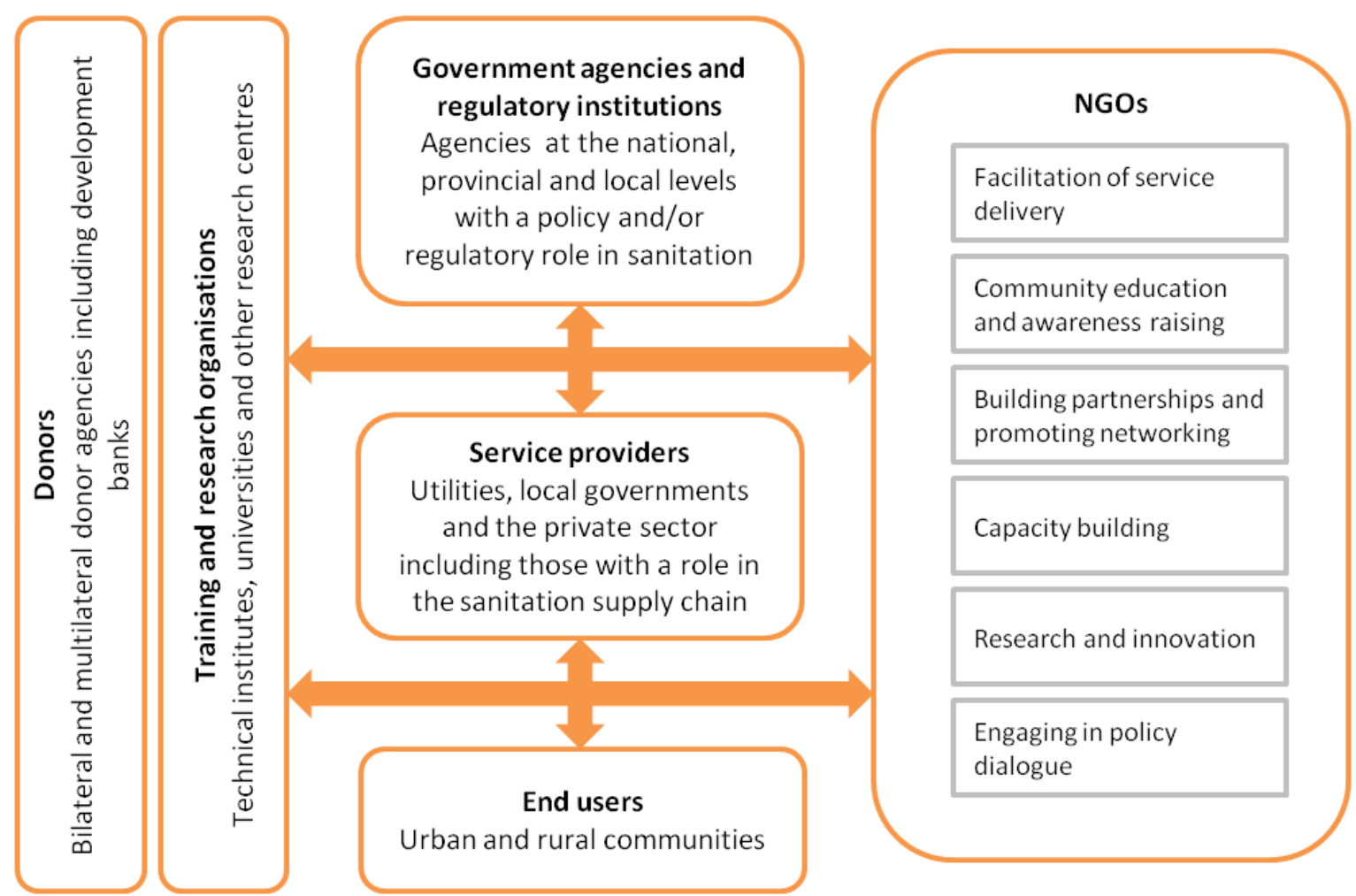

Figure 2 Sanitation sector actors and roles played by NGOs - opportunities for engagement

In practical terms, maximising the benefits of working with NGOs in the sanitation sector requires action from both NGOs and other sector actors. NGOs could better coordinate their initiatives with other activities including investing in networking and knowledge sharing across the NGO community to improve sector wide capacity (particularly technical capacity in relation to sanitation approaches and technologies). In facilitating service delivery, NGOs need to design projects that focus on sustainable business models and capacity building for self-replication, for example communities that teach and facilitate action in other nearby communities.

For service providers including local governments and utilities, NGOs could be engaged to help facilitate community consultation and inform the design of appropriate sanitation service delivery options. Service delivery in both rural and urban areas still often take place without adequate focus on the necessary "software" elements like education and community mobilisation that will make real the associated health benefits of sanitation. NGOs, with their history of strong community centred approaches, could be engaged to investigate the cultural acceptability of different sanitation options in different contexts including ability and willingness to pay, current sanitation practices and likely successful behaviour change strategies. NGOs could provide training for local service providers and could play a role in stimulating local markets including capacity building for small scale private sector service providers and development of sanitation supply chains. IDE in Vietnam, for example, has successfully piloted a market based approach informed by detailed community surveys to identify acceptable solutions and define targeted behaviour change strategies and facilitated through locally managed microfinance schemes and capacity building for local supply chain organisations.

NGOs are well placed to contribute grounded perspectives to policy dialogues and share experiences about lessons learnt including successful approaches. There are opportunities for government agencies to draw on NGO functions as 'interface' actors in the sanitation sector to facilitate inter-agency information sharing and link local experiences with national level policies 
and strategies. There is potential for government agencies to engage NGOs to provide 'value-add' services to national strategies including capacity building, behaviour change programs, monitoring and evaluation and other 'software' aspects of sanitation initiatives. There are opportunities for government agencies to build relationships with NGOs to work closely with communities, particularly where government resources and outreach are not sufficient, for example in remote rural areas or peri-urban settlements. In peri-urban settlements in particular, NGOs are wellequipped to identify and respond to the cross-cutting issues of poverty, gender, land rights and social inequalities that challenge conventional service provision by utilities. Mercy Corps in Indonesia is an example of an NGO providing expertise and support to utilities in this area, and in Surabaya a planned World Bank initiative will likely include NGO involvement at the community interface.

Working closely with donors and other partners, NGOs can also play a much greater role in the scale-up of approaches that have proven successful in a localised context. International NGOs in particular are often operating in a number of countries and can use their global networks to help adapt successful models and approaches with proven on-ground outcomes. NGO work can often be characterised as following a cycle of 'innovate-demonstrate-advocate to replicate'. This cyclical and reflexive approach offers a potential vehicle for increasing sanitation coverage and usage, particularly when supported by the donor community. Perhaps the most dramatic example of this is the NGO-developed CLTS approach, which has already been responsible for rapid increases in sanitation usage throughout South Asia and is being taken up in the national sanitation policies of countries like Indonesia. As noted above, CLTS in Timor Leste has already been piloted by several NGOs, who have demonstrated its outcomes and advocated the approach at the national level. Equally, in other places such as the Philippines and the Pacific, NGOs have played a key role in developing eco-sanitation approaches that ensure sustainable recycling of nutrients as well as a safe sanitation option, particularly in areas where water is scarce.

NGOs, with their strong focus on partnerships, also offer an effective means for enhancing capacity of government, civil society, communities and households to meet sanitation needs. INGOs in particular will not be based in a community for the long-term, and therefore typically emphasise the transfer of skills and knowledge to local partners including provincial government agencies and local service providers. There are opportunities for NGOs to engage with training and research organisations to share lessons and transfer knowledge about successful capacity and skills building approaches.

\section{CONCLUSION}

NGOs can and do make a unique contribution to the sanitation sector and more incentives should be put in place to support that contribution. Emphasis should be placed on building better links between NGO activities and the activities of other actors including government agencies and service providers at local, provincial and national level. This requires both NGOs to proactively seek to work in partnership with other sector actors, and for other actors including governments, utilities and the private sector, to recognise the benefits NGOs bring to sanitation initiatives and create opportunities for collaboration. This paper has characterised six significant NGO roles in the sanitation sector and illustrated how these roles translate to practice in Vietnam and Timor Leste. While the practical experiences of NGO engagement will vary in different contexts the lessons are broadly applicable, and consideration of NGO roles and strengths is a useful framework through which different actors can consider strategies to maximise the benefits of NGO engagement in the sanitation sector. 


\section{ACKNOWLEDGEMENT}

This paper is based on research funded by the Australian Agency for International Development (AusAID).

\section{REFERENCES}

Bartram, J., Lewis, K., Lenton, R. and Wright, A. (2005) Focusing on improved water and sanitation for health. The Lancet. 365(9461), 810-812.

Cairncross, S. (2003) Sanitation in the developing world: current status and future solutions. International Journal of Environmental Health Research. 13(Supplement 1), S123-S131.

Curtis, V. and Cairncross, S. (2003) Effect of washing hands with soap on diarrhoea risk in the community: a systematic review. The Lancet Infectious Diseases 3(5), 275-81.

de Bruijne, G., Geurts, M. and Appleton, B. (2007). Sanitation for All? IRC Thematic Overview Paper 20. The Netherlands: IRC International Water and Sanitation Centre.

Government of Timor-Leste (GoTL) (2007) Water Supply and Sanitation Priorities and Proposed Sector Investment Program, Government of Timor-Leste, Dili.

Hardi, A. (2000) A participatory approach to sanitation: experience of Bangladeshi NGOs. Health Policy and Planning. 15(3), 332-337.

Lahiri, S. and Chanthaphone, S. (2003) Water, sanitation and hygiene: a situation analysis paper for Lao PDR. International Journal of Environmental Health Research. 13(Supplement 1), S107-S114.

Obika, A. 2004. The process for sanitation marketing. WELL Fact Sheet. Available at www.lboro.ac.uk/well/resources/fact-sheets.

Robinson, A. (2007) Rural Sanitation in Timor-Leste Current Practices and Policy Options, IDSS.

Robinson, A (2008) Rural Sanitation in Timor-Leste Policy Options and Development Process, IDSS.

Sustainable Sanitation Alliance (SuSanA) (2007). Towards more sustainable sanitation solutions. SuSanA Statement Draft, May 2007.

UNICEF (2007) A Summary of National Baseline Survey on Environmental Sanitation and Hygiene Situation in Viet Nam, UNICEF Viet Nam and the Viet Nam Administration of Preventative Medicine, Ministry of Health.

Visscher, J.T., E. Uytewaal, J. Verhagen, C. Da Silva Wells, M. Adank (2006). Gaining Insight into Capacity Development at the Local Level. Background Paper on the Symposium for Sustainable Water and Sanitation: Strenthening Capacity for Local Governance, 26-28 September 2006, Delft, the Netherlands: IRC and UNESCO-IHE.

WaterAid (2006) WaterAid Submission to the International Development Select Committee Inquiry into Water and Sanitation.

Water Supply and Sanitation Collaborative Council (WSSCC) and World Health Organisation 
(WHO). (2005). Sanitation and Hygiene Promotion Programme Guidance. Geneva: WSSCC and WHO.

Willetts, J., Pedi, D., Carrard, N., Powell, B. And de Lacy, I. (2008) NGO Partnerships and Capacity Building in the Water, Sanitation and Hygiene Sector, report for AusAID, available at http://www.isf.uts.edu.au/publications/willettsetal2008ngowash.pdf.

World Health Organization and United Nations Children's Fund (2008) Progress in Drinking Water and Sanitation: special focus on sanitation, Joint Monitoring Programme for Water Supply and Sanitation. UNICEF, New York and WHO, Geneva. 